\title{
Conservation and Maintenance Concepts of Soong Ching Ling's Dolomite Marble Statue in Shanghai and Supporting Survey Methods
}

\author{
Tianyue Qin ${ }^{1}$, Yijie Wang ${ }^{1}$, Jingyi Li $^{1}$, Zhong Tang ${ }^{1,2}$, Shibing Dai ${ }^{1,2, *}$ \\ ${ }^{1}$ Dept. of Architecture, College of Architecture and Urban Planning, Tongji University, 1239 Siping Road, Shanghai, P.R. China - \\ ada_q@tongji.edu.cn, lyan_0316@qq.com,2732589247@qq.com,tangzzzk@163.com, ds_build@163.com \\ ${ }^{2}$ Architectural Conservation Laboratory, Tongji University, 1239 Siping Road, Shanghai, P.R. China
}

KEY WORDS: Dolomite Marble, Soong Ching Ling's Statue, Photogrammetry, Conservation, Monitoring.

\begin{abstract}
:
The dolomite marble statue of Madam Soong Ching Ling, Honorary Chairlady of the People's Republic of China, is situated in the memorial square of Soong Ching Ling's Mausoleum in Shanghai, China. The statue is composed of 4 pieces of white marble (Hanbaiyu) from Fangshan, Beijing. The statue, along with the mausoleum, has been listed as a national monument since 1982, yet severe deterioration occurred in recent years. In May 2018, a diagnostic investigation of the statue was carried out. Aided by advanced photogrammetry methods such as 3D modelling, macro photography and infrared thermography, all micro cracks were identified and labelled. Other advanced in-situ and laboratory surveys such as in-situ microscope, ultrasonic CT inspection, chalking evaluation test and mineralogical investigation were applied to further evaluate the condition. Based on analysis of all test results, conservation and maintenance concepts including a monitoring program specifically to control cracking has been developed. This concept was approved by the authorities and implemented in May 2019. After two years' exposure, an evaluation of previous conservation and a new maintenance work were recently completed in April 2021. A long-term monitoring strategy as well as maintenance methods will be worked out based on the evaluation of all implemented efforts and climatic data.
\end{abstract}

\section{INTRODUCTION}

\subsection{General Introduction}

Madam Soong Ching Ling was Honorary Chairlady of the People's Republic of China. In February 1982, Soong Ching Ling's Mausoleum was listed by the State Council as a National Key Cultural Relics Protection Unit. On January $10^{\text {th }}, 1984$, Soong's mausoleum was expanded and named as "Mausoleum of Soong Ching Ling, Honorary Chairlady of the People's Republic of China" by the Central Government. The whole park consists of a monument on the mausoleum avenue, a memorial square, a statue of Soong Ching Ling (Figure 1), a mausoleum, and a display room. The statue of Soong Ching Ling is located on the north side of the memorial plaza in the mausoleum and is 2.52 meters high with a 1.1-meter-high base. The statue is based on the figure of Soong Ching Ling when she was about 50, wearing a cheongsam and the rounded collar top she wore on her visit to Ceylon (now Sri Lanka), with her hair in a bun and her hands folded in her lap, smiling.

The stone used for the statue was white marble, known as "Hanbaiyu", a kind of valuable artistic natural dolomite marble from Fangshan, Beijing. Due to the size of the stone, the statue was assembled in two parts.

On January $27^{\text {th }}, 1984$, the 91 st anniversary of Soong Ching Ling's birth, an inaugural ceremony was held at the Soong Ching Ling's Mausoleum in Shanghai.

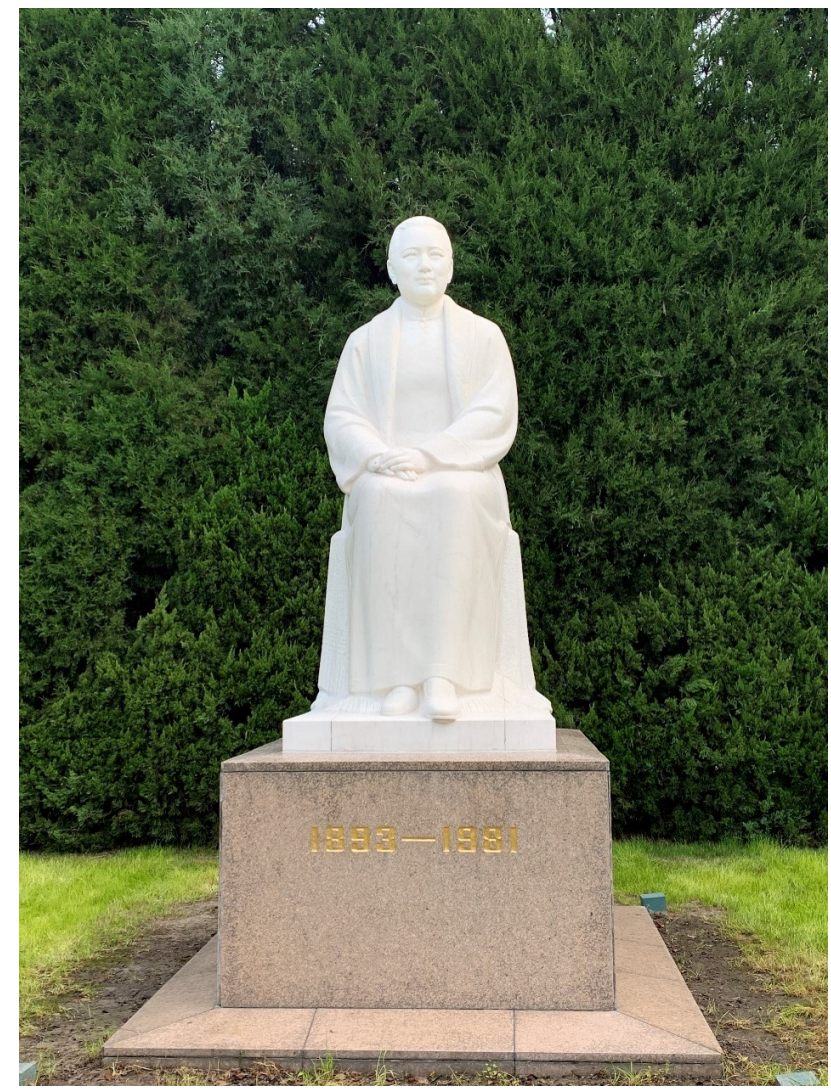

Figure 1. Soong Ching Ling's dolomite marble statue, 2021, Shanghai, P.R. China. (Source: Zhong Tang)

\footnotetext{
* Corresponding author
} 


\subsection{History of Conservation}

In November 1990, the mausoleum management asked the Shanghai Paint Institute to clean the statue and then cover it with white paint. In March 1991, the statue was repainted with a kind of polyurethane-acrylic transparent paint with a titanium dioxide pigments and fillers. In March 2010, the white paint on the surface of the statue was washed off. A transparent impregnator based on silicone resin was applied with intention to reduce the water absorption and slow down the deterioration without evaluating the statue's condition.

However, over the past few years, there has been significant cracking and chalking on the statue and a tendency of visible deterioration, as well as moss and bird droppings pollution (Figure 2). Initial tests revealed that the silicone water-repellent protective layer has now largely failed. To delay further development of the disease which could lead to significant damage, a professional survey is required on the statue's current state to analyze the diseases and provide a scientific basis for proposing more effective and sustainable maintenance methods.
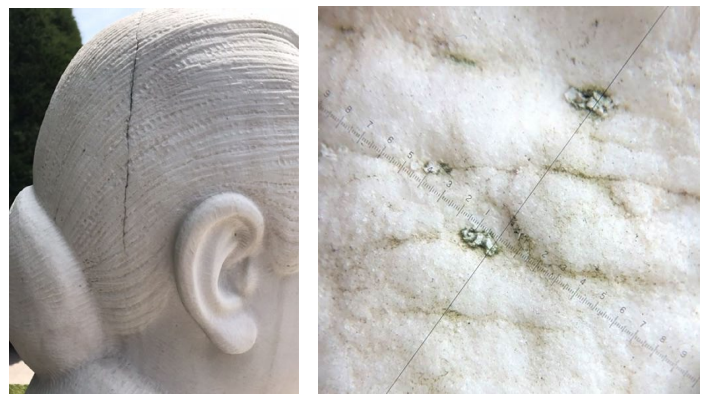

Figure 2. Deteriorations on the statue: cracks, chalking, moss, old paint photo taken in May 2018. (Source: Tongji-ACL)

\section{DOCUMENTATION METHODS}

\subsection{D Model}

The statue of Soong Ching Ling is not suitable for long-term scaffolding observation, so a 3D model needs to be built for laboratory observation and locating its damage. The modelling uses close-range photogrammetry, with intensive multi-angle professional acquisition of high-resolution images, and image processing with professional image recognition modelling software (Agisoft PhotoScan Professional Edition) to create a 3D Point Cloud model, which in turn generates a Mesh Model, and finally gives a Texture Map to the surface. Based on the 3D model, an orthographic projection map can also be generated so that cracks can be measured accurately after eliminating perspective distortion.

A total of 228 high-resolution images (5456x3632 20M pixels each) were taken in-situ (Figure 3), with 20,026 points of feature connectivity, generating a dense point cloud of $9,088,425$ points and a 3D mesh model of $1,600,036$ surfaces. With the 3D model, the laboratory can closely observe and analyze the number and distribution of deteriorations on the surface of the statue through computer and can precisely locate and label them to provide references for the next step of field work (Figure 4).

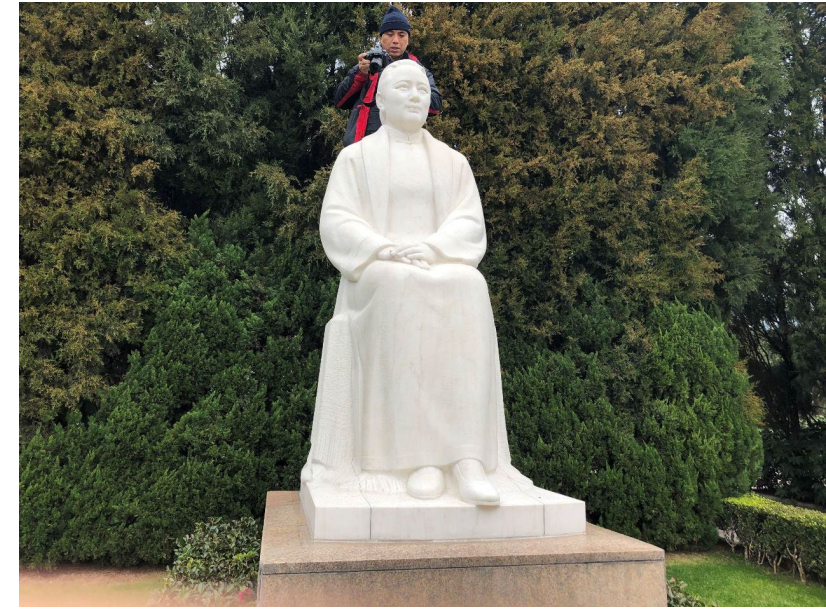

Figure 3. Documentation undergoing, 2019. (Source: TongjiACL)
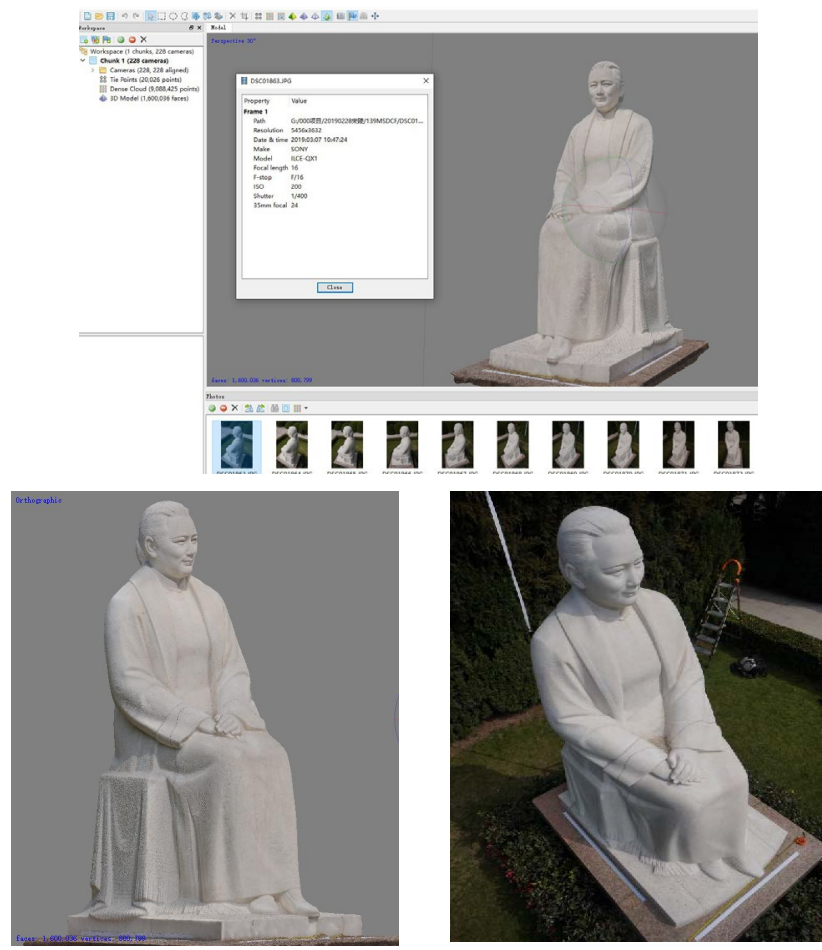

Figure 4. 3D modelling in process and the final digital model, with its perspective distortion eliminated, comparing with the real photo of the statue. (Source: Zhong Tang)

\subsection{Macro Photography}

The texture mapping of the photographic modelling surface is derived from the field acquisition of high-resolution maps. As a 3D model mapping, the resolution is limited by the field acquisition image resolution, software calculation settings and hardware calculation capabilities. For the laboratory to observe and locate the disease, the 3D model requires a resolution of 2 pixels $/ \mathrm{mm}$ (i.e., a pair of black and white pixels per millimeter of image), for a $1 \mathrm{~mm}$-sized crack to be distinguished. The total height of the statue is $2.52 \mathrm{~m}$, or $2520 \mathrm{~mm}$, for which a total of 5040 pixels for the image height are required.

The in-situ shooting conditions were ideal, with more space to use longer focal lengths and directly get photos with relatively 
little perspective distortion as an emergency method to observe and locate the disease as soon as possible. The actual in-situ output of the Nikon D800E camera was 36.3 million pixels (7360 x 4912) in total, with a single full body image's resolution of nearly 3 pixels $/ \mathrm{mm}$.

For local deteriorations, the macro photography method was adopted, using a professional macro lens with a magnification ratio of up to $1: 1$ and a resolution of over 200 pixels $/ \mathrm{mm}$. In practice, due to the limitation of the lens' resolution and the conditions of the shooting site, it was ensured that gaps over $0.05 \mathrm{~mm}$ wide could be distinguished.

\subsection{Infrared thermography (IRT)}

Near the cracks of stone, especially the deep ones, the temperature appears to differ from the surrounding intact stone. Thermal infrared imaging can reflect the temperature field of the object surface by imaging the object with thermal infrared sensitive CCD, so that the cracks can be visually located.

The original resolution of FLIR t660 hand-held infrared thermal imager is $640 \times 480$, which can provide 307,200 pixels and UltraMax image enhancement function, with temperature resolution $<0.02^{\circ} \mathrm{C}$.

Through the in-situ infrared thermal imaging of the statue, it is found that although there were many cracks all over the surface of statue, the most obvious temperature difference was located at a vertical crack on the upper right side of the head (Figure 5), which means that the depth of this crack was deeper and more severe than other cracks. This preliminary judgment was later confirmed and quantified by the following tests.
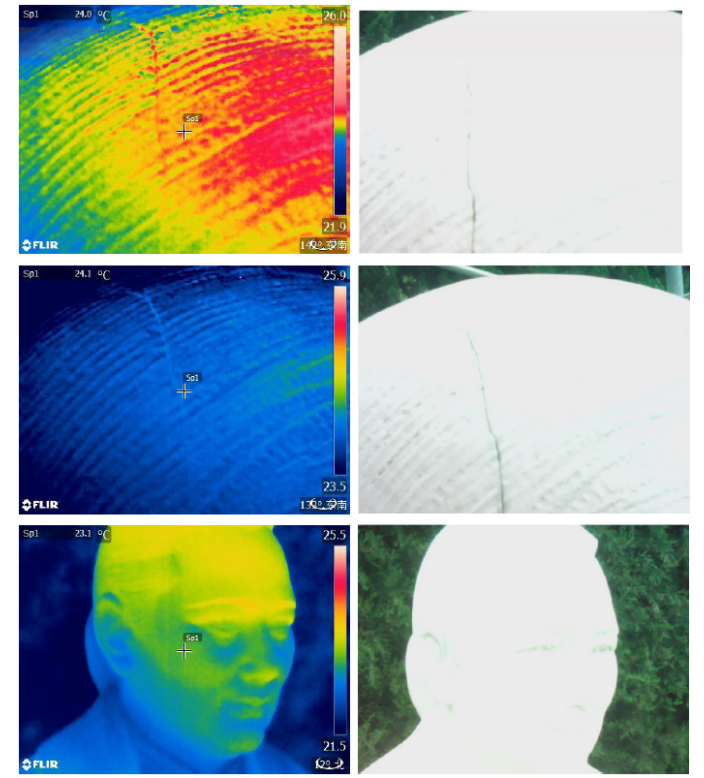

Figure 5. Comparison of IRT images and real photos of the statue's head. (Source: Tongji-ACL)

\subsection{Crack Mapping}

According to Chinese industry standard WW/T 0002-2007

Classification and Legend on the Deterioration of Ancient Stone
Objects and relevant German standards, mappings of every visible crack on the statue and recording of their disease status were completed in 2019. Every visible crack was numbered with 3 characters corresponding to its orientation, part of statue, and sequence so that it could be clearly identified in later surveys and conservation studies (see Figure $6 \& 7$ as examples).

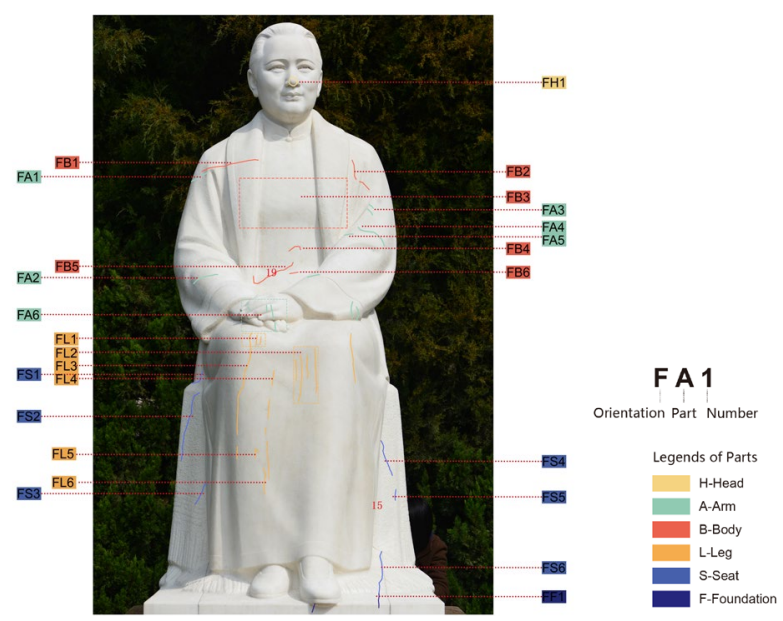

Figure 6. Mapping of cracks on the front of the statue, with the labelling rules illustrated. (Source: Yijie Wang, Tianyue Qin)

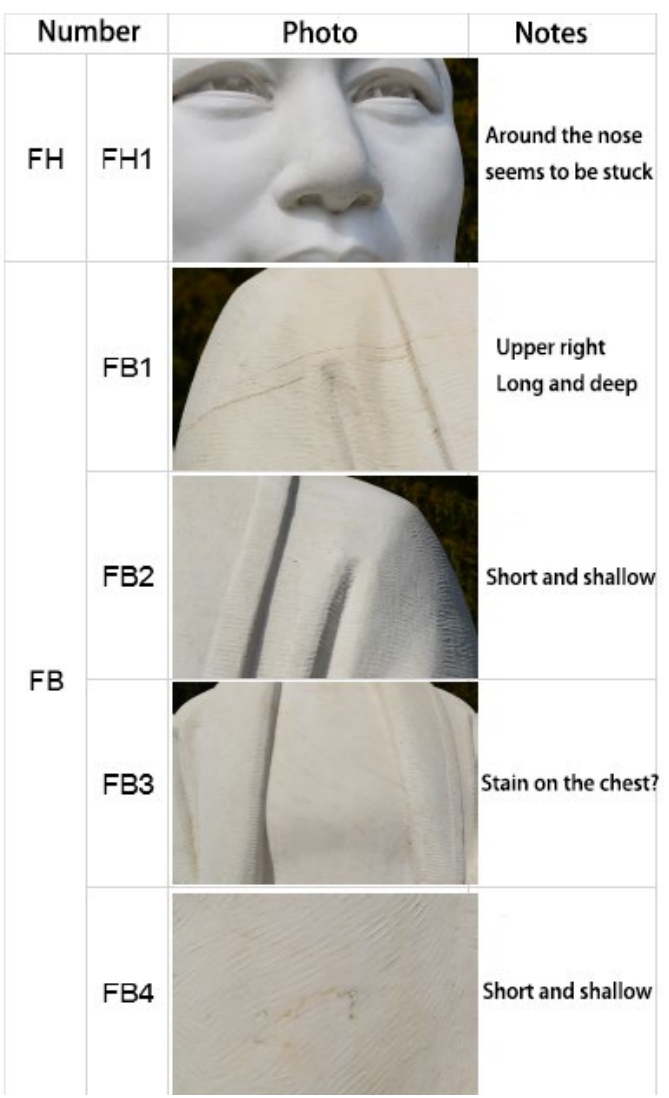

Figure 7. Detailed recordings of every visible crack including its number, a close-range photo and description. (Source: Yijie Wang, Tianyue Qin) 


\section{IN-SITU AND LABORATORY SURVEYS}

\subsection{In-situ Microscope}

Due to the immobility and non-destructibility of the statue, a Nikon hand-held microscope, a portable observation microscope and a crack width observation instrument were used to record and analyze the color, cracks, and microscopic characteristics on surface (Figure 8).
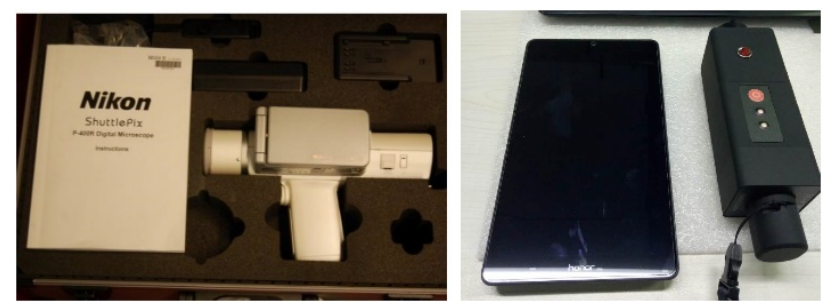

Figure 8. The Nikon hand-held microscope and the crack width observation instrument. (Source: Tongji-ACL)

Over 30 micro cracks were identified and labeled under the insitu microscopes. The dolomite crystal fabric on the surface wore off with different degrees, and even small marble pieces were peeling off (Figure 9).
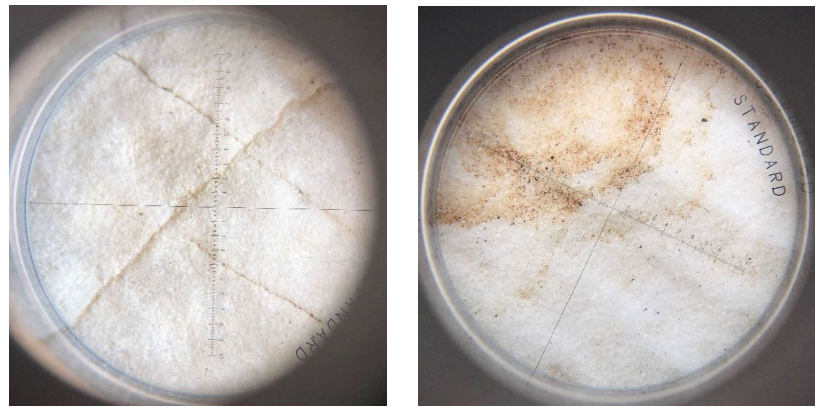

Figure 9. Under the in-situ portable microscope: cracks and bird droppings pollution. (Source: Tongji-ACL)

\subsection{Ultrasonic CT Inspection}

While previous testing methods were used to quickly identify, locate, and qualitatively determine visible cracks in the appearance of the statue in the field, this project collaborated with the Shaanxi Provincial Institute of Cultural Heritage Protection to quantify the depth of cracks using its selfdeveloped complete ultrasonic CT testing system.

The inspection was carried out using a combination of the ultrasonic $\mathrm{CT}$ method and the crack depth detection method according to CECS21:2000. The more serious cracks in the head of the statue were detected by ultrasonic CT (Figure 10), while cracks on other parts were detected by the crack depth detection method.

Ultrasonic CT inspection of the statue's head revealed through data analysis several facts about the cracking condition of the statue. No obvious massive cracks were visually found on the surface of the left back of the head of the statue, but according to the CT test results, there were two deeply developed cracks of a depth of approximately $50 \mathrm{~mm}$. Obvious cracks whose depths ranged from $10-50 \mathrm{~mm}$ according to the $\mathrm{CT}$ test results were found on the surface of the right back of the head of the statue. In addition, the ultrasonic CT mapping revealed that surface deterioration (the beginning of loosening of the crystal structure of the stone) of a thickness of $10-20 \mathrm{~mm}$ (some up to $50 \mathrm{~mm}$ ) was prevalent on the surface of the statue of Soong Ching Ling, which should be given sufficient attention (Figure 11).
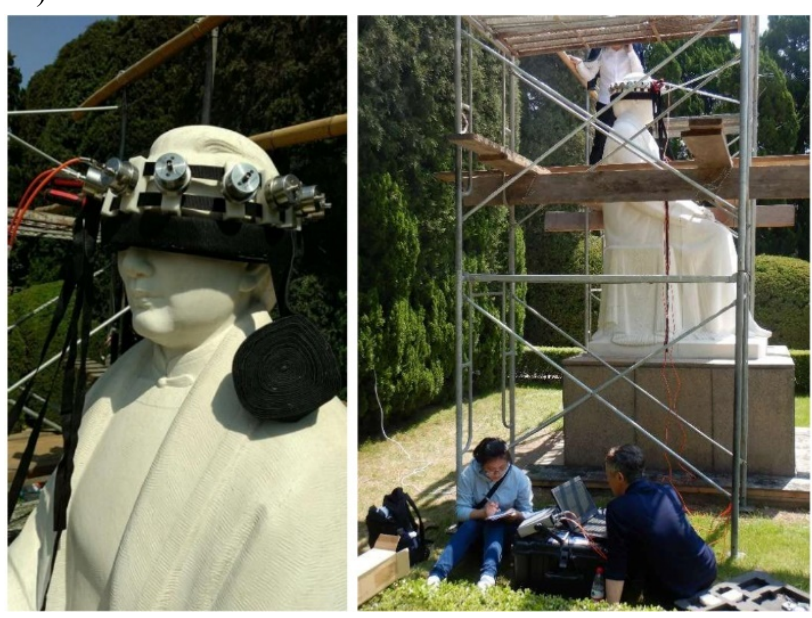

Figure 10. Conducting the ultrasonic CT inspection on statue's head. (Source: Tongji-ACL)
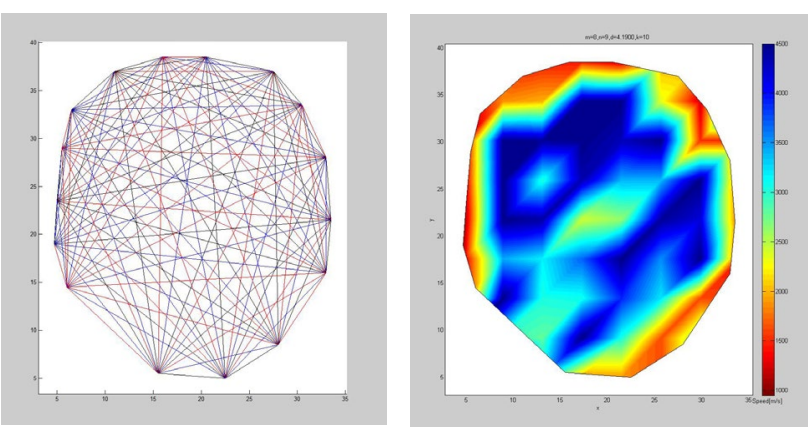

Figure 11. Ultrasonic detection data and CT mapping, showing a general deterioration of the marble on the head's surface. (Source: Honglin Ma)

The cracks in other parts of the statue were detected according to the crack depth detection method specified in CECS21:2000 Technical Specification for the Detection of Concrete Defects by Ultrasonics. A total of 15 cracks were selected for in-situ measurements, including 6 transverse cracks and 9 longitudinal cracks. After detection and data analysis, the depth of different cracks is found to vary from $0 \mathrm{~mm}$ to $63 \mathrm{~mm}$. The depth of different parts in the same crack varied. Some small cracks were found on the surface, yet their depth was basically $0 \mathrm{~mm}$, which means they were probably developed by the joints of the stone itself rather than the stress within the statue. 


\subsection{Chalking Evaluation Test}

Stone cultural heritage undergoes surface chalking during natural deterioration. The quantitative determination of chalking allows, on one hand, to assess the degree of surface deterioration of cultural heritage, and on the other hand, to quantitatively monitor and assess the quality of technical measures such as surface curing and their durability.

Learning from the methods for determining surface chalking DIN EN ISO 2409, GBT9286-1998 "Scratch test for color and varnish paint films" and ISO8502-3 for determining the adhesion of chalked stone surfaces, the laboratory has developed a method, tool, and process for the quantitative determination of surface chalking on inorganic non-metallic materials (Figure 12\&13).

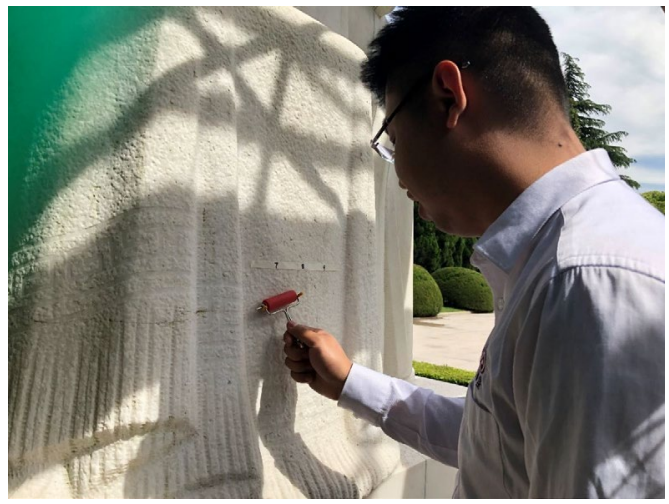

Figure 12. Conducting the chalking evaluation test on the side of the statue in May 2019. (Source: Tongji-ACL)
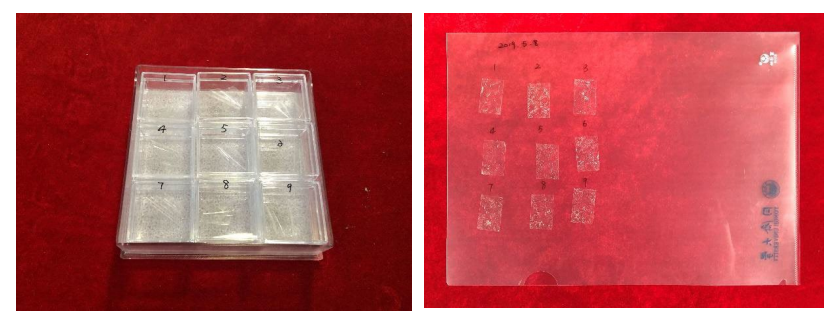

Figure 13. Laboratory analysis of the chalking evaluation test. (Source: Tongji-ACL)

The chalking of the surface of the white marble on different sides of the statue was found to vary considerably between the east and north sides, with chalking levels ranging from 0.32 to $0.70 \mathrm{mg} / \mathrm{cm}^{2}$ and 0.14 to $0.53 \mathrm{mg} / \mathrm{cm}^{2}$, respectively. The chalking levels of three test points at different locations on the west side were similar, ranging from 0.51 to $0.54 \mathrm{mg} / \mathrm{cm}^{2}$. Comparison of the average value on different sides showed that the chalking on the west side was more severe.

The dolomite marble is a kind of metamorphic stone, which has extremely low porosity and water absorption. During natural weathering and environmental impacts, the water absorption would increase, which could be measured and evaluated with help of Karsten Test Tube. However, it was impossible to test the water absorption of the statue due to the leakage of water through invisible chalking of the surface (Figure 14). This can be verified by the ultrasonic test results showing surface deterioration of the dolomitic marble.

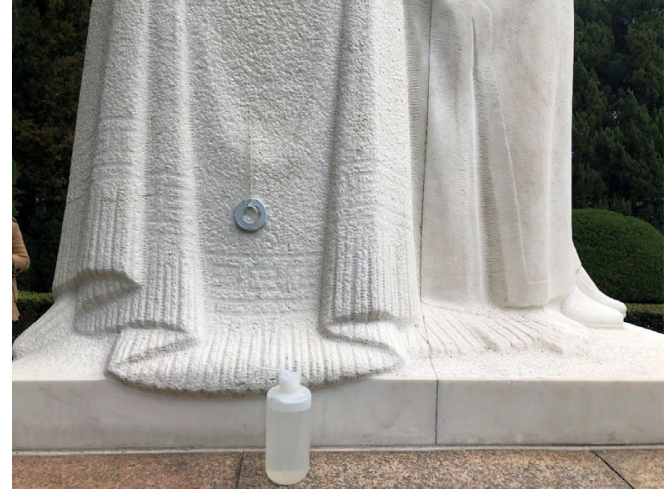

Figure 14. Water leaks from the sealed marble during water absorption test using Karsten's Test Tube. (Source: TongjiACL)

\subsection{Mineralogical Investigation}

The stone of Soong Ching Ling's statue is described as white marble from Fangshan, Beijing. Literature research shows that this type of white marble is composed of mainly dolomite( $92-97 \%$ in volume), sericite, quartz, and other minerals.

XRD (X-ray diffraction), by diffracting the material and analyzing its diffraction pattern, is a research tool to obtain information on the composition of the material, the structure or morphology of the atoms or molecules within the material (Figure 15).
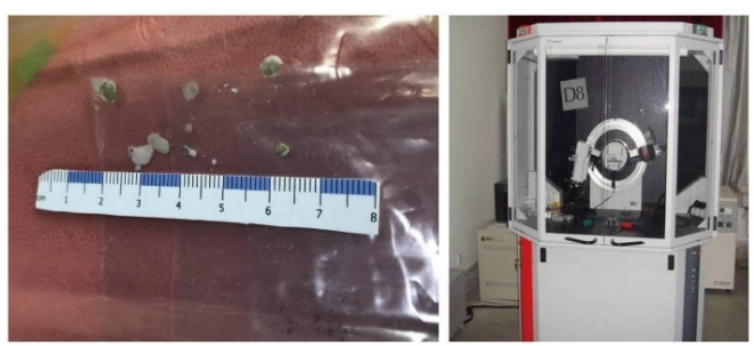

Figure 15. Specimens to be analyzed (left) and the X-ray analyzer (right). (Source: Tongji-ACL)

The XRD results showed that the main composition of the white marble used in Soong Ching Ling's statue was dolomite $\left(\mathrm{CaMg}\left(\mathrm{CO}_{3}\right)_{2}\right)$. Specimen 1 contained $90 \%$ dolomite $\left(\mathrm{CaMg}\left(\mathrm{CO}_{3}\right)_{2}\right)$ and $9 \%$ quartz $\left(\mathrm{SiO}_{2}\right)$. Specimen 2 contained $60 \%$ dolomite $\left(\mathrm{CaMg}(\mathrm{CO} 3)_{2}\right), 24 \%$ magnesium sulphate crystals $\left(\mathrm{MgSO}_{4} \cdot 7 \mathrm{H}_{2} \mathrm{O}\right)$ and $14 \%$ ferrous oxide $(\mathrm{FeO})$ (Figure 16).

This has proven that the white marble comes from Fangshan in Beijing. However, it has already undergone chemical weathering with airborne chemicals, especially $\mathrm{SO}_{2}$.
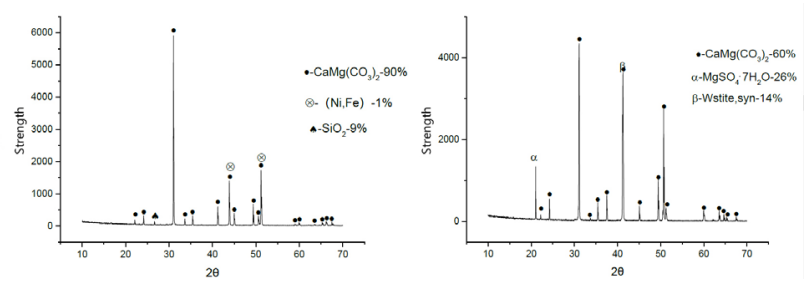

Figure 16. XRD analysis results of two specimens. (Source: Tongji-ACL) 


\section{CONSERVATION AND MAINTENANCE CONCEPTS BASED ON SURVEY RESULTS}

Since the statue of Soong Ching Ling is exposed to the outdoor environment, it is impossible to prevent air pollutants, acid rain and temperature difference from harming the statue. Therefore, the conservation and maintenance methods should adhere to the following concepts and principles:

1) DO NOT change the original state of this cultural relic.

2) DO NOT change the color of the statue's surface. Hold the correct and coherent aesthetic standard. This means the finishing of natural dolomite marble shall be preserved and displayed to visitors.

3) Choose correct and suitable maintenance methods and materials to ensure the safety of this cultural relic.

4) Ensure ecological security by protecting the statue and its surrounding environment.

5) Enhance the regular maintenance of the statue.

Based on analysis of all survey and laboratory conservation test results, conservation and maintenance concepts including a monitoring program specifically to control cracking has been developed. The conservation program of the statue mainly includes desalination with compressor to remove magnesium sulfates, crack injection and surface consolidation with micronano lime, crack repair with lime-dolomite powder. A sacrificial layer based on nano-lime shall be applied to the entire surface to protect authentic dolomite marble. This concept was approved by the authorities and implemented in May 2019.

The statue shall be maintained every year based on visual inspection and minor-destructive tests, including the ultrasonic test and other comparative tests.

After two years' exposure, an evaluation of the previous conservation and a new maintenance work were recently completed in April 2021. The results will be published in the next paper.

\section{CONCLUSION AND DISCUSSION}

The Madam Song's Statue is a unique monument, which cannot be replaced by new materials like most architectural elements from dolomite marble. The durability of dolomite marble in extremely polluted outdoor exposure is compromised. There are no successful conservation practices to guide the daily maintenance. Therefore, a new comprehensive research framework needs to be developed to understand the deterioration of dolomite marble in Shanghai climate, to maintain the monument with sustainable techniques. All the quality control tests shall be verified with minimally destructive test methods.

\section{ACKNOWLEDGMENTS}

The research was supported by NSFC Grant No.51978472. Soong Ching Ling's Mausoleum administration office and
Zhejiang DESAIBAO Ltd are thanked for their cooperation as well as Zheng He, Yue'e Zhou, Lei Li \& Faling Ju of the Architectural Conservation Laboratory of Tongji University, Shanghai.

\section{REFERENCES}

Auras, M., Meinhardt, J., Snethlage, R., 2010. Leitfaden Naturstein-Monitoring - Nachkontrolle und Wartung als zukunftsweisende Erhaltungsstrategien. Fraunhofer IRB Verlag.

Die WTA-Merkblätter der Wissenschaftlich-Technischen Arbeitsgemeinschaft für Bauwerkserhaltung und Denkmalpflege e.V. WTA Merkblatt3-4-90/D, Natursteinrestaurierung nach WTA X: Kenndatenermittlung und Qualitätssicherung bei der Restaurierung von Natursteinbauwerken.

IFS-Bericht, 2003. Umweltbedingte Gebäudeschäden an Denkmälern durch die Verwendung von DolomitKalkmörteln.

J.García-León, P.E. Collado Espejo, F. J. Jiménez González, 2019. Negro Tower: Documentation, Conservation and Restoration. International Archives of the Photogrammetry, Remote Sensing and Spatial Information Sciences - ISPRS Archives, v 42, n 2/W15, p 489-496, August 19, 2019. doi: 10.5194/isprs-archives-XLII-2-W15-489-2019.

Knöfel, D., Schubert, P., 1993: Handbuch Mörtel und Steinergaenzungsstoffe in der Denkmalpflege. Berlin: Verlag Ernst \& Sohn.

National Cultural Heritage Administration of P.R. China. $W W / T$ 0002-2007, Classification and Legend on the Deterioration of Ancient Stone Objects.

Reul, Horst, 2007. Handbuch Bautenschutz und Bausanierung, 5.Auflage. Cologne: Rudolf Müller.

Shibing Dai, Peng Zhang, 2014. Proposed Technical Guidelines for Conservation of Historic Architectural Materials. Shanghai: Tongji University Press.

Tao Zhang, Dongqing Li, Zhongjian Zhang, 2016: Study on the Disease Types and Mechanism of the Marble Relics in Beijing. Geotechnical Investigation \& Surveying, 44(11):7-13.

Zhang Qu, 2018. The Research on the Weathering Mechanism and Weathering Degree Evaluation System of Marble Relics in Beijing. (Master), Beijing University of Chemical Technology. 